\title{
Users That Do Personalizing Activity Toward Their Belonging
}

\author{
Dandi Yunidar ${ }^{1}$, Ahmad Zuhairi Abdul Majid ${ }^{2}$, Hardy Adiluhung ${ }^{3}$ \\ ${ }^{1}$ Product Design, Telkom University, Bandung, Indonesia \\ ${ }^{2}$ Product Design, Universiti Sains Malaysia, Penang, Malaysia \\ ${ }^{3}$ Product Design, Telkom University, Bandung, Indonesia \\ dandiyunidar@telkomuniversity.ac.id (Dandi Yunidar), majid.zuhairi@usm.my (Ahmad Zuhairi Abdul Majid), hardyadi@yahoo.com \\ (Hardy Adiluhung).
}

\begin{abstract}
This research is based on the belief that "the Asian people prefer more colorful interfaces with images rather than plain interfaces" (Tzvetanova, 2007) [2]. The previous research conducted by Tzvetanova was about interface, the question is what if it's a three dimensional form of daily use product? Will the same preferences and tendencies happen when it comes about daily use product such as laptop? There are evidences that people add stickers on their laptop, which brings up question like "what kind of users and what drives them do such activity toward their laptop?" To add/put stickers on the laptop makes it looks more literally colorful, and it also makes the laptop feels more personal. Using simple Psychographic method compared with Emotional design [1] approach, the authors made description about users who did put stickers on their laptop and dug out about what drives them did such activity. In turn this research will provides information and recommendation for the industries to be considered that there are some others crucial aspects regarding user preferences and user behavioral tendencies, rather than just technical aspect as they develop their products and massproduce it, in order to be accepted by end users.
\end{abstract}

Keywords Emotional design, Personalizing, Laptop

\section{Introduction}

Emotional design plays important role in $21^{\text {st }}$ century product development, since most people in so many countries enjoy a high standard of living [4]. Nowadays there are so many daily use products that are designed and manufactured in massive quantities and become more meaningless to us as person. As a unique individual, most of us try to personalize our belonging and add personal value to our belonging just to make sure that this thing is mine, and not yours.

Norman mentioned on his book: Emotional Design, that the best designs are the ones we create for ourselves. He also stated that if we create our own design, that would be the most appropriate design which is functional and aesthetic for our self [1].

This research is highlighting an actual event that occurs in Telkom University where some of its lecturers and students actually put sticker/stickers on their laptop (Figure $1)$.

Based on the belief what Tzetanova found on her previous research that the Asian people prefer more colorful interfaces

with images rather than plain interfaces [2]. The case brings up questions like; are they creating their own version of "Attractive, Colorful, and Fun" Because of their prefabricated laptops are way too boring for them?

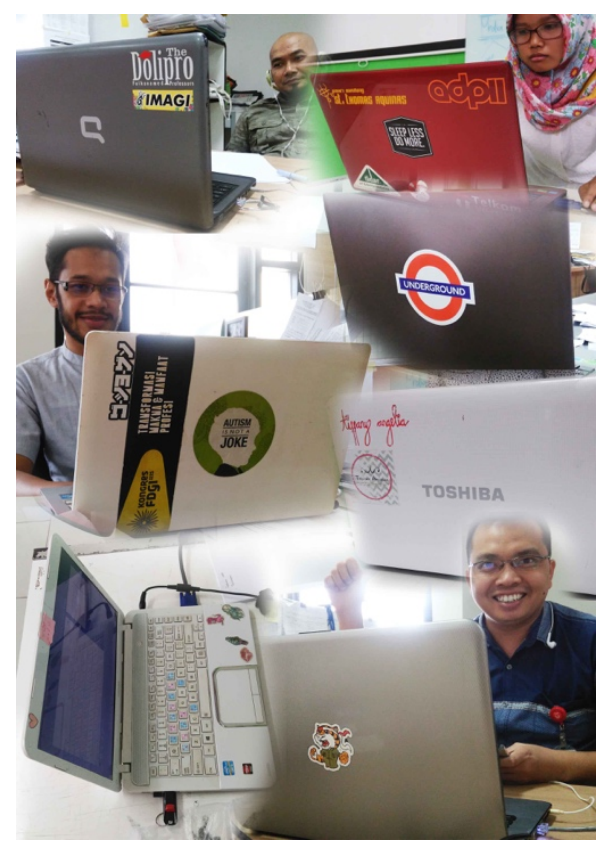

Figure 1 The Usage Stickers on Laptop in Telkom University 
To answer the question then we have to understand what kind of users tend to do such activity toward their belonging (laptop).

The purpose of this paper is to describe how to construct users description that do such activity toward their belonging.

\section{Method}

\subsection{Groups and Positive Statements in Set Questionnaires}

The questionnaires divided into four sections that contain three positive statements in each section. The sections as follow:

a. Character : The character section of this questionnaire consist three positive statements to describe participants character tendencies, whether he/she is a active, reactive or passive kind of person.

b. Goal Orientation : The Goal Orientation section of this questionnaire consist three positive statements to describe participants commitment tendencies, whether he/she has strong, average or weak (realistic) will to get things done to reach their goal.

c. Lifestyle : The Lifestyle section of this questionnaire consist three positive statements to describe participants lifestyle tendencies, whether he/she has intention for luxurious (consumptive), normal or simple lifestyle.

d. Self-Confidence : The Self Confidence section of this questionnaire consist three positive statements to describe participants self confidence tendencies, whether he/she is Overconfidence, self-confidence or self-conscious.

Every statement in this questionnaire is a positive sentence that does not offend any participant in any way. each section in this questionnaire affects each other and creates a simple overview of the respondent type, which can ultimately provide information about the respondent preference (lecturers and students in Telkom University).

\subsection{The Values}

There are three values to indicate user behavioural tendency in every questionnaire section. These values are as follow :

a. Character section : In this section the values are indicated with terms like
Active : people with this character tend to be more expressive, brave, and like to be in charge.

Reactive : people with this character tend to be more calm, tolerance, but they are always ready to get involve.

Passive : people with this character tend to be more practical, easy going, and playing by the book.

b. Goal Orientation : In this section the values are indicated with terms like

Strong : This indicates he/she has strong will to get things done at all cost.

Average : This indicates he/she will get things done but they also very adaptive to any circumstances.

Realist : this indicates he/she will get things done only when it could be done.

c. Lifestyle : In this section the values are indicated with terms like

Consumptive : this indicates he/she likes to have or choose luxurious things in life.

Normal : this indicates he/she likes to have easiness in life.

Simple : this indicates he/she chooses function and efficiency over luxurious.

d. Self-confidence : In this section the values are indicated with terms like

Over-confidence : this indicates he/she is over-confidence but in positive way.

Self-confidence : this indicates he/she is self-confidence but in positive way.

Self-conscious : this indicates he/she is uncomfortable/uneasy with his/her self.

All those value indicators are set to describe user preference when they faced to issues that are not related with their daily life in practical.

\subsection{Results}

After being filled by the participants the questionnaires compiled then calculated, and the outcome as shown bellow (Table 1). We can read from that table below that in section 1 , the majority of the participants answered "OK", which indicates that most of them are "Reactive" kind of persons. In section 2 of the questionnaire most of them answered "Agree" which indicates that they have strong will to get things done when they already set the goal. In section 3 most of them also answered "agree", which indicates that they do like to have or choose luxurious things in life. And so is in section 4 most of them choose "Agree", which indicates that they are very confidence people.

Table 1. Result of questionnaire calculation

\begin{tabular}{lccc} 
Section & Agree & Ok & Disagree \\
\hline Section 1 & 8 & 21 & 1 \\
\hline Section 2 & 18 & 9 & 3 \\
\hline Section 3 & 16 & 8 & 6 \\
\hline Section 4 & 15 & 12 & 3 \\
\hline
\end{tabular}


The results of the distributed questionnaires show trends about the values of life and the character of the participants themselves (Figure 2).

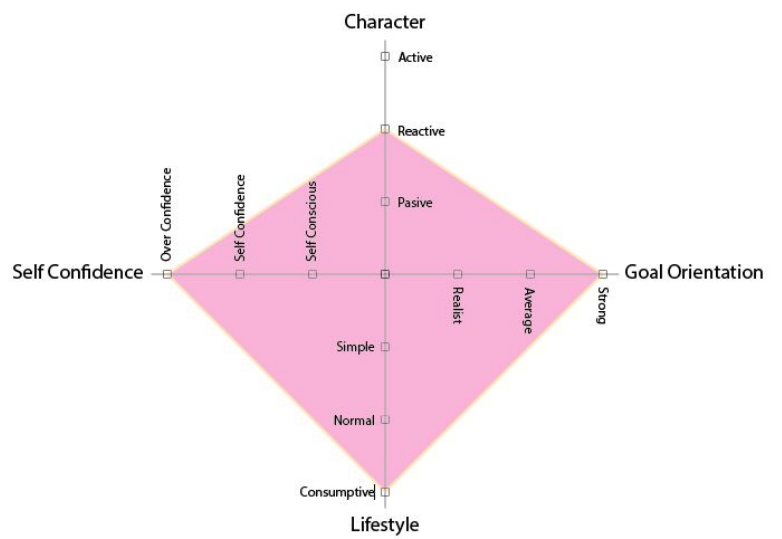

Figure 2. The majority results from filled questionnaire by participants.

\subsection{Discussion}

The radar chart of the questionnaire result provides us with information about the participants (Figure 2). From that chart we can assume that the majority of participants are people with reactive character, they have strong will to achieve their goal, they also enjoy luxurious things and quite consumptive, and they tend to be very confidence.

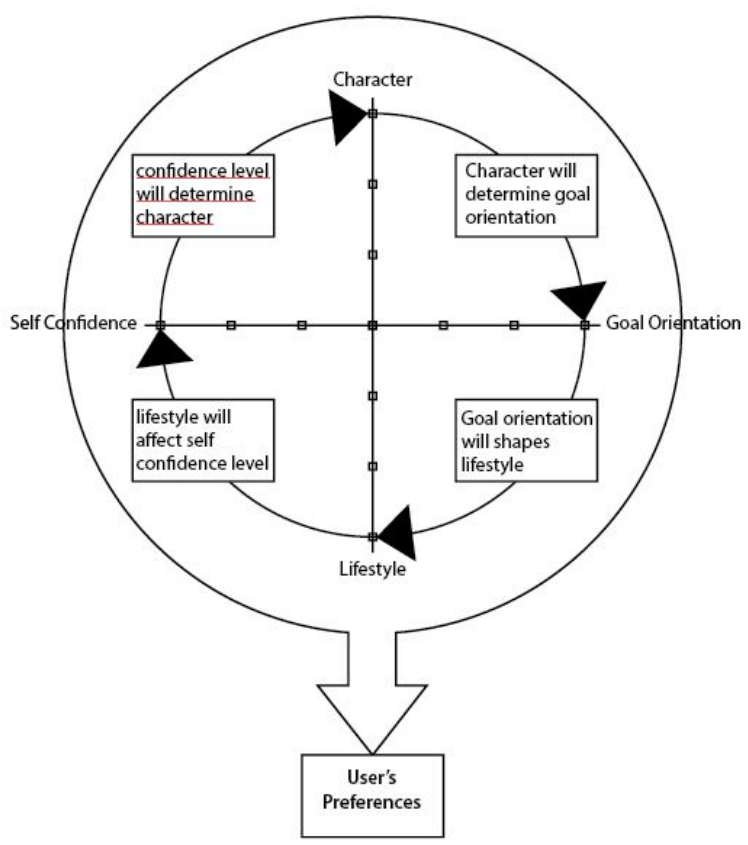

Figure 3. The four parameters relationship.

The four parameters like character, goal orientation, lifestyle and self confidence were chosen because there is a relationship between the four and affect each other. The character will determine user's will (goal orientation), the user's will toward their goal would of course shapes their lifestyle (the way they life, the way they think, etc), and user's lifestyle will also affect their self confidence level, and in turn the self confidence level will finally determine user's character. This never ending circular relationship between the four parameters will determine what kind of user he/she is, and finally will render their preferences (Figure 3).

\section{Conclusions}

In 2001, Goebert and Rosenthal mentioned that "The real problem had nothing to do with the product's intrinsic value, but instead represented the emotional connection that links a product to its user" [6]. This statement could be a valuable clue about how big the gap between a product with its user.

Most of prefabricated products like laptop were sold to and used by the user who never involved when its being created, and accepted the product (laptop) from the seller in original state as it produced by the manufacturer. Its function as a working tool is the only connection between the product (laptop) with the user. In Norman term it is very behavioral [1]. For passive kind of user that would be no problem at all as they are very function-minded and mind only behavioral kind of things [1]. But for reactive kind of user that may be a problem, moreover for active kind of user that might be a major problem.

So to answer the question about "what kind of users do the personalizing activity toward their belonging", it is clear that most of lecturers and students in Telkom University are reactive kind of users according to the questionnaires. And of course the reactive kind of users tend to be more emotional rather than the passive one, and they also capable to create or to add something that has nothing to do with practical function as long as they like the appearance, and make them happy. And yes they are creating their own version of "Attractive, Colorful, and Fun" just because they can and have a confidence to do it.

\section{REFERENCES}

[1] Norman, Donald A., Emotional Design, Why We Love or Hate Everyday Things, New York, United States: Basic Book, 2004.

[2] Tzvetanova, S., Emotional Interface Methodology. International Association of 50 Societies of Design Research, (IASDR), 2007.

[3] Si Jie Phua, Wee Keong Ng, Haifeng Liu, Bin Song, Xiang Li, A Rule Mining Approach To Emotional Design In Mass Customization, International Conference on Engineering Design, ICED 2007.

[4] Yomaoka, Toshiki., An Emotional Design Method Based on Human Design Technology, Proceeding of International Association of Societies of Design Research (IASDR) 2009, pp 4435-4443.

[5] Abdul Majid Ahmad Zuhairi, Shaari Nazlina., Design Strategy For Designing a Service in Malaysia, International Service Innovation Design Conference, Hakodate, Japan, 2010.

[6] Goebert, B., \& Rosenthal, H. M. Beyond listening: Learning the secret language of focus groups. New York: J. Wiley. 2001. URL for chapter 1: Listening 101: The Value of Focus Groups.http//www.wileyeurope.com/cda/cover/0,04713956 $25 \% 7$ Cexcerpt, 00 .pdf 